\title{
HUGE CERVICAL FIBROID MIMICKING AN OVARIAN TUMOR
}

\author{
Alka Dani1 ${ }^{1}$, Sriram Gopal2, Prashant Roplekar³
}

\section{HOW TO CITE THIS ARTICLE:}

Alka Dani, Sriram Gopal, Prashant Roplekar. "Huge Cervical Fibroid Mimicking an Ovarian Tumor". Journal of Evolution of Medical and Dental Sciences 2015; Vol. 4, Issue 27, April 02; Page: 4701-4704,

DOI: $10.14260 /$ jemds/2015/680

ABSTRACT: Uterine leiomyoma are most common benign tumor of the uterus but cervical fibroids are rare. They usually manifest in pressure symptoms, pain and lump abdomen or irregular vaginal bleeding. But sometimes presentation is unusual. We are reporting a case of huge cervical fibroid mimicking ovarian tumor due to hyaline and haemorrhagic changes. Even though we have modern diagnostic modalities like USG, CT scan and MRI, sometimes diagnosis is only confirmed on laparotomy.

KEYWORDS: Cervical Fibroid, Ovarian tumor, leiomyoma.

INTRODUCTION: Fibroid or leiomyoma is a most common benign solid tumor of not only the uterus but female pelvis also.[1] Incidence of uterine fibroid is 20\% while, cervical fibroid which arises from cervical wall is rare and account for $1-2 \%$ of all fibroids.[2] It may arise either from supravaginal part of cervix or vaginal part of cervix. Cervical fibroid is usually interstitial or subserous and rarely it is submucosal and polypoidal.[2] Cervical fibroids are usually asymptomatic or can cause pressure symptoms like increased urinary frequency and burning micturition and constipation, lump and pain in abdomen and irregular vaginal bleeding. Large cervical fibroids may mimic an ovarian tumor.[1,3] It can distort the pelvic anatomy, displaces the ureter to lateral side hence utmost care should be taken while operating to prevent ureteric injury.

CASE REPORT: A 45 year old patient presented to emergency unit with complaints of pain in abdomen for 8 to 10 days with acute exacerbation since 6 - 8 hrs, with increased frequency and burning micturition. Her pain was sharp in nature, non-radiating and more in left iliac fossa. She had her last menses 6 months back. Before that her periods were irregular @interval of 2 to 3 months. She had two normal deliveries and tubectomy was done 16 years back. There was no history of weight loss, decreased appetite and constipation. She had no significant medical or surgical illness. On general and systemic examination, all findings were normal. Patient was obese. Pulse was 88 per minute; B.P. was 130/ 80. Heart and lungs were normal on auscultation. Abdominal examination revealed a large ill-defined solid cystic mass in left lumbar and left iliac fossa arising from pelvis. Tenderness was present on deep palpation. Per speculum examination revealed that cervix was pulled up and visualized with difficulty. On bimanual examination uterus was found to be retroverted, exact size could not be made out. A large soft solid cystic mass of $\sim 12 \mathrm{~cm}^{*} 10 \mathrm{~cm}$ in size, extending up to the lateral pelvic wall, tender non-mobile, and inseparable from the uterus felt through left fornix and a small $5 \mathrm{~cm} * 4 \mathrm{~cm}$ sized firm rounded mass felt through right fornix on the right side of the uterus. Left fornix was very tender. On per rectal examination, large irregular solid cystic mass felt in mid-line and extending up to the left lateral pelvic wall. It was very tender and a small firm round mass felt on the right side of uterus. Rectal mucosa was free. On investigation her $\mathrm{Hb}$ was $11.6 \mathrm{gm} \%$, blood sugar, liver and renal function test, ECG, X-ray chest were normal. 
Tumor marker CEA was $3.11 \mathrm{IU} / \mathrm{ml}$ (normal) \& CA 125 was $49.47 \mathrm{IU} / \mathrm{ml}$ (raised). Ultrasound report showed uterus of normal size with a large left adnexal mass of $12.5 \mathrm{~cm} * 6 \mathrm{~cm} * 3.7 \mathrm{~cm}$ and a subserosal posterior wall fibroid of $4 \mathrm{~cm} * 3.7 \mathrm{~cm}$ size. Left ovary was not seen separately from the adenexal mass. Right ovary was normal in size and shape. CT scan of abdomen and pelvis showed a large well defined soft tissue attenuation lesion in left adnexa measuring $\sim 12 \mathrm{~cm} * 6 \mathrm{~cm} * 6.5 \mathrm{~cm}$ in size, right sided intramural fibroid of $5 \mathrm{~cm} * 3.8 \mathrm{~cm}$ in size with mild hydronephrosis and hydroureter due to $0.6 \mathrm{~cm}$ sized ureteric stone on left side. IVP showed no calculi with normal renal function and contour on both side. IV antibiotics and IV fluids were administered to the patient pre operatively.

Exploratory laparotomy under regional anesthesia revealed large cervical fibroid of $\sim 12 \mathrm{~cm}$ * $10 \mathrm{~cm}$ on the left side another fibroid of $5 \mathrm{~cm} * 5 \mathrm{~cm}$ arising from the right lateral wall of uterus and extending into the broad ligament. One more tiny fibroid was present on the anterior surface of uterus. Both tubes and ovaries were normal (Fig. 1). Bowel loop and omentum were adherent to the posterior surface of the cervical fibroid near infundibulopelvic ligament. Total abdominal hysterectomy with bilateral salpingoopherectomy was done after enuecleation of fibroids and adhesionolysis by sharp dissection. Postoperative period was uneventful except wound gaping for which secondary suturing was done. Histopathological (Fig. 2) report revealed cervical fibroid with hyaline changes and two uterine leiomyoma.

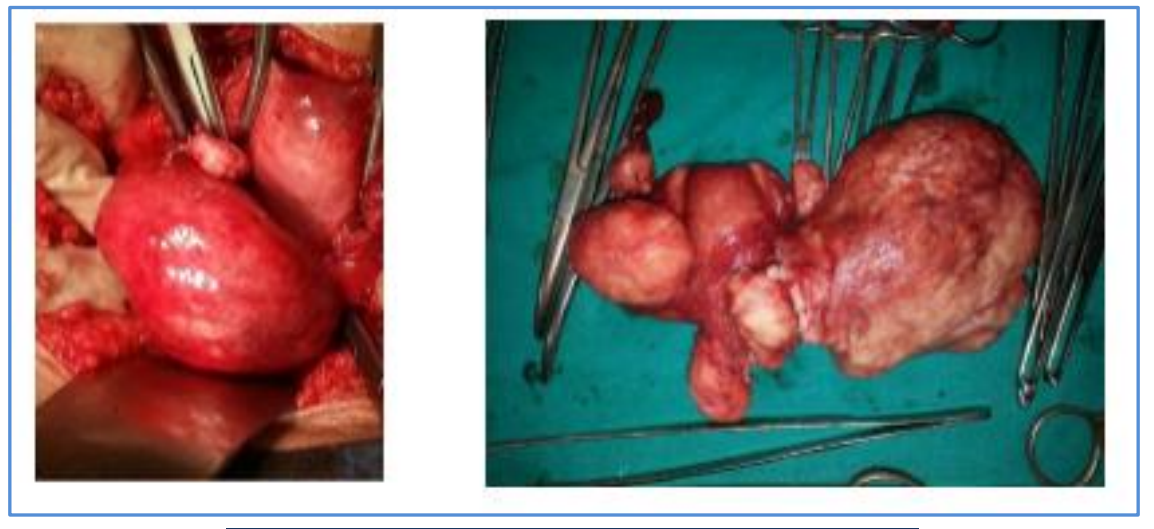

Fig. 1: Uterus with cervical Fobroid

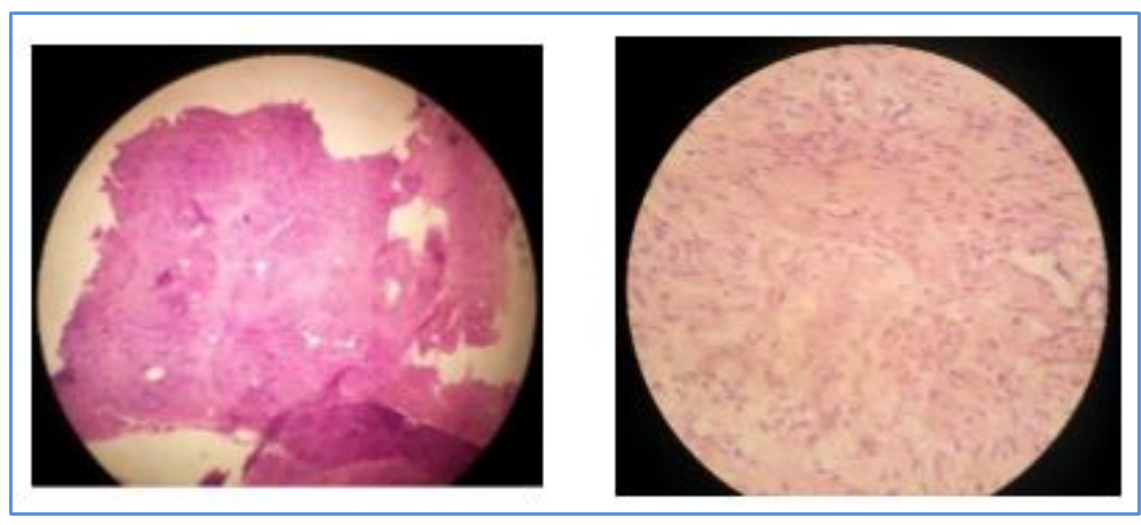

Fig. 2: Histopathological slides showing fibroid with hyaline changes 
DISCUSSION: Huge cervical fibroids are rare. These fibroids can distort the pelvic anatomy, pushes the bladder up, ureters are pushed laterally and uterine vessels are also pushed up and laterally, making these structures more prone to injury during surgery.[4] Sharma et.al.[5] reported a case of cervical fibroid that clinically resembles an ovarian tumor. During surgery left ureter was injured and ureteric anastomosis was done in that case. Basnet et.al.[6] also reported a case of huge cervical fibroid with an unusual presentation. Bladder was injured during surgery and repair was done. Bilateral internal iliac artery ligation was done to achieve complete hemostasis. The principle to be followed to prevent injury to bladder, ureter and uterine vessels is enucleation of fibroid followed by hysterectomy as ureters and uterine vessels are always extracapsular.

CONCLUSION: Cervical fibroids are usually irregular, firm to hard in consistency but in this case due to secondary degenerative changes (Hyaline and haemorrhagic) it was soft and solid cystic and tender and was mimicking an ovarian tumor clinically. Ovary was not seen separately from the mass on USG and CT scan and CA125 was raised. Even though we have modern diagnostic modalities like USG, CT scan and MRI, sometimes diagnosis is only confirmed on laparotomy.

\section{REFERENCES:}

1. Dutta DC, Benign lesion of the uterus. In: Konar H, eds. Textbook of Gynaecology Including Contraception. $5^{\text {th }}$ ed. Kolkata: New Central Book Agency (P) Ltd., 2009: 262 - 264.

2. Bhatia N, Tumours of the corpus uteri. In: Jeffcoates Principles of Gynaecology. $5^{\text {th }}$ ed. London: Arnold Publisher; 2001470.

3. Suneja A, Taneja A, Guleria K, Yadav P, Agarwal N, Incarcerated procidentia due to cervical fibroid: An unusual presentation. Aust N Z J Obstet Gynaecology 2003; 43: 252-253.

4. Kshirsagar SN, Laddad MM. Unusual presentation of cervical fibroids: Two case reports. International J of Gynae Plastic Surgery, 2011; 3(1): 38 - 39.

5. Sharma S, Pathak N, Goraya SP, Singh A, Mohan P. Large cervical fibroid mimicking an ovarian tumor. Sri Lanka J Obstet Gynaecol 2001; 33 26-27.

6. Basnet N, Banerjee B, Badani U, Tiwari A, Raina A, Pokharel H. An unusual presentation of huge cervical fibroid. Kathmandu Univ Med J (KUMJ) 2005; 3: 173 - 174. 


\section{CASE REPORT}

\section{AUTHORS:}

1. Alka Dani

2. Sriram Gopal

3. Prashant Roplekar

\section{PARTICULARS OF CONTRIBUTORS:}

1. Assistant Professor, Department of Obstetrics \& Gynaecology, Dr. D. Y. Patil Medical College, Hospital \& Research Centre, Nerul, Navi Mumbai.

2. Professor, Department of Obstetrics \& Gynaecology, Dr. D. Y. Patil Medical College, Hospital \& Research Centre, Nerul, Navi Mumbai.

FINANCIAL OR OTHER

COMPETING INTERESTS: None
3. Professor, Department of Pathology, Dr. D. Y. Patil Medical College, Hospital \& Research Centre, Nerul, Navi Mumbai.

\section{NAME ADDRESS EMAIL ID OF THE}

\section{CORRESPONDING AUTHOR:}

Dr. Alka Dani,

Flat No. 204, Chaurang CHS Ltd,

Plot No. 4, Sector 16, Sanpada,

Navi Mumbai-400705.

E-mail: alka.dani@gmail.com

Date of Submission: 18/03/2015.

Date of Peer Review: 19/03/2015.

Date of Acceptance: 23/03/2015.

Date of Publishing: 02/04/2015. 